\title{
DEVELOPMENT OF A VALUE ADDED BEVERAGE FROM MATURED COCONUT WATER.
}

\author{
BY
}

ISURI SARANGA GAJANAYAKA

Thesis submitted to the university of Sri Jayawardanapura for the award of the Degree of Master of Science in food science and tecnology on June 2006. 
We certify that the above statement made by the candidate is true and that this thesis is suitable for submission to the university for the purpose of evaluation

$28 / 11 / 06$

Date

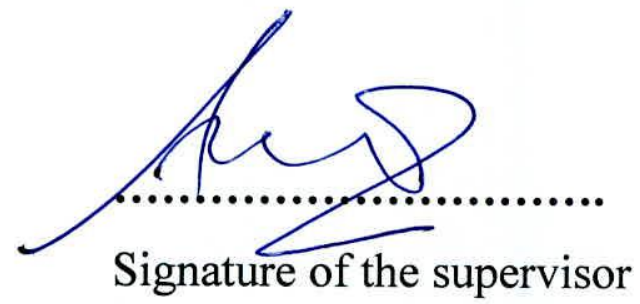

Prof. A Bamunuarachchi.

The Head.

Dept of Food Science

University of Sri Jayawardanapura

\section{Date}

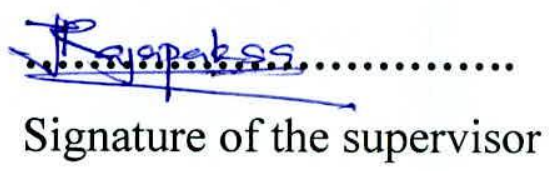

J. Rajapakssa.

Werapagalla Mills

Veyangoda 
The work described in this thesis was carried out by me under the supervision of Prof . A. Bamunuarachchi and Mr. C.J. Rajapaksha, and a report on this has not been submitted in whole or in part to any University or any other instituton for another Degree / Diploma.

$20 \cdot 11: 2006 . \ldots$

Date

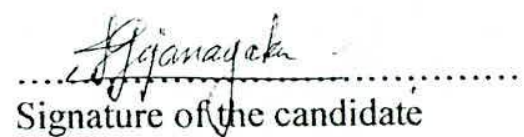




\section{Table of contents}

\section{Chapter 01 -Introduction}

1.1 Introduction............................................. 01

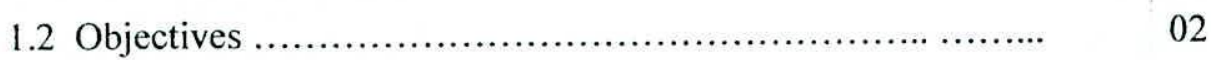

\section{Chapter 02- Literature Review}

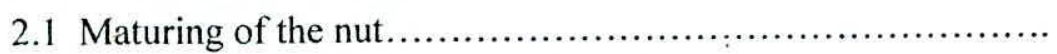

2.2 Chemical constituents

2.2.1 Sugars.........................................

2.2.2 Minerals........................................ 05

2.2.3 Proteins........................................ 06

2.2.4 Vitamins...................................... 07

2.2.5 Fat.......................................... 07

2.3 Effervescence And Flavor................................ 07

2.4 Medicinal Properties.................................... 08

2.5 Coconut water

2.5.1. Water of the matured nut.......................... 09

2.5.2. compositions of coconut water.................... 11

2.6 Keeping Quality of Tender coconut...................... 14

2.7 Packing Technologies

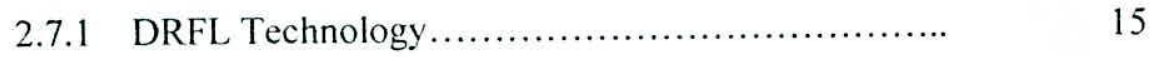

2.7.2 FAO Technology.............................. 16

2.7.3 RRL Technology.............................. 16

German Technology...................................... 17 


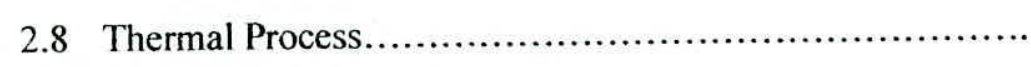

\subsection{Ingredients used}

2.9.1 Sugar.

2.9.2 Ascorbic acid.................................. 18

2.9 .3 Citric acid...................................... 19

2.10 Factors for successful Production of Coconut Water Beverages... 20

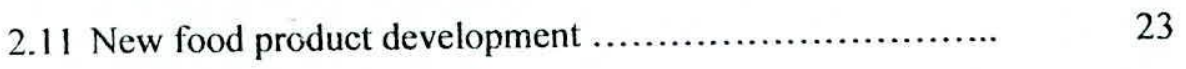

2.12 Shelf life evaluation. ................................. 25

2.13 Sensory Evaluation of foods. .......................... 25

2.13.1. Types of tests. ............................... 26

2.13.2. The Hedonic Scale.......................... 27

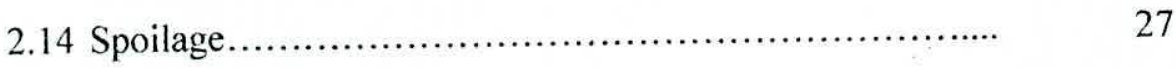

2.14 .1 Browning.......................................... 27

2.14.2 Microbial Changes. .............................. 28

2.15 Factors Affecting the growth of micro Organisms.......... 28

\section{Chapter 03- Experimental}

3.1 Materials................................................ 29

3.1.1 Formulation..................................... 29

3.1.2.Chemical Analysis............................. $\quad 30$

3.1.3. Microbiological Analysis......................... 30

3.1.4. Sensory Evaluation................................ 31

3.1.5. Marketing Survey.............................. 31 
3.2. Methods.................................................... 31

3.2.1. Formulation....................................... 31

3.2.2. Chemicai Testing................................. 33

3.2.3. Microbi $₫ i c a l$ Analysis............................. 34

3.2.4. Sensory Analysis ................................

3.2.5. Marketing survey .................................. 35

3.2.6. Shelf life Analysis............................... 36

\section{Chapter 04 - Results And Discussion}

4.1 Marketing Survey........................................

4.2 Formulae used ......................................... 40

4.3 Microbial Quality ........................................ $\quad 40$

4.4 Sensory Analysis .................................... 41

4.5 Selecting the best formulae .............................. 41

4.6 Shelf life observations .................................. 43

\section{Chapter 05 - Conclusion}

1.1 Conclusion .............................................

1.2 Suggestions and recommendation ..................... 44

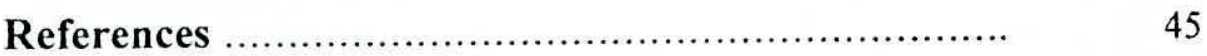

\section{Appendices}

7.1 Questionnaire for market survey 
7.2 Questionnaire for rank sum...................... 48

7.3 Questionnaire for Hedonic scale.................... 49

7.4 Sensory evaluation using SAS .................... 50

7.5 Analysis of data of sensory evaluation............... 51

7.6 Microbial counts............................... 52

7.7 Questionnaire for paired comparison test............ 53

7.8 Analysis of paired comparison test................ 54 


\section{List of Tables}

Table $01 \quad$ Total reducing sugar and protein content................ of coconut water from nuts of Various stages.

Table 02 Average analysis of coconut water...................... ? ?

Table $03 \quad$ Characteristic ranking according to consumer preference 38

Table $04 \quad$ Self life observations. ................................. 43

\section{List of figures}

Figure $01 . \quad$ Chemical structure - ascorbic acid.................... 18

Figure $02 . \quad$ Chemical structure - citric acid ...................... 19

Figure 03. Graphical presentation and of reference for serving size... 37

Figure 04. Graphical presentation and of reference for level of sweetness 37

Figure 05. Graphical presentation and of reference for package........ 38

Figure 06. Graphical presentation and of reference for Keeping quality.. 38 


\section{Acknowledgments}

Firstly I express my deepest gratitude to my internal supervisor Prof A.Bamunuarachchi, the co-ordinater, Masters in food science and technology, University of Sri Jayawardanapura. for his patience, continuous encouragement and guidance, and spending his valuable time in bringing this study to a successful completion.

I express my special thank to Mr. C. Rajapaksha, The propriter, Werapagalla mills ,Weyangoda; for his guidance and permission to visit and carryout research work as an when necessary, throughout the study. I wish to extend my thanks to all the members of the staff of Werapagalla mills for their numerous contributions throughout the study.

I must also express my sincere gratitude to Dr.K.K.D.S.Ranaweera, the present coordinater, Masters in food science and technology, University of Sri Jayawardanapura for his ready guidance and tremendous support, in directing my studies towards success.

I further extend my thanks to Laboratory staff, of the food science laboratory of University of Sri Jayawardanapura for their kind co-operation and assistance in analysis work and sample preparation.

Finally I gratefully acknowledge the constant assistance of my loving parents, brothers, sisters and my dear friends, which inspired me towards success. 


\title{
Development of a value added beverage from Matured coconut water. By Isuri Saranga Gajanayaka
}

\begin{abstract}
Tender fruit of the tropical monocotyledon Cocos nucifera is know: as coconut. It's liquid endosperm is a refreshing drink: Fresh from the nut to people in tropical countries and as a value added beverage to consumers world wide. Coconut is a major exporting item of Sri Lanka. Paring of coconut is done in large scale for production of desiccated coconut, copra and spray dried coconut powder, where only the solid endosperm is used. This leaves out the liquid endosperm, which cause environmental problems when disposed to surrounding area, but has a high demand if presented as a value added beverage in certain countries. Therefore it is important to establish, beyond question a method of production for a value added product from matured coconut water to profitably utilize a by-product in coconut processing industry leading to a cleaner production.
\end{abstract}

A preliminary marketing survey and market leading brands of coconut water beverage was used to gain an idea about consumer perception of a coconut water beverage. It revealed that the preferred beverage required lower sweetness, good taste, easy to use cans of $325 \mathrm{ml}$ serving size and 3 month shelf

The best process was collection of coconlit water and diluting it to reduce the matured flavour to go by with tender coconut water. Then formulating adding sugar up to 6 brix, Citric and ascorbic acid in 2:1 ratio to reduce $\mathrm{pH}$ and control browning. Then filled to 


\section{Chapter 01}

\subsection{Introduction}

The demand for natural drinks all over the world is on an increasing trend since the health conscious consumers are increasing. The coconut is gaining an importance as a beverage crop through out the world.

Mostly coconut water is still consumed fresh in tropical coastal areas. Once exposed to air the liquid rapidly looses most of its organoleptic and nutritional characteristics, and begin to ferment.

Commercial production of tender coconut water is mainly carried out in Philippines, Indonesia and Thailand. To retain flavour and natural characteristics sophisticated technologies as UHT, Micro filtration, centrifugation etc is practiced. Hence the Production process is very technological and expensive. The taste of tender coconut and matured coconut differ significantly due to compositional changes that take place with the maturity of the nut. But thermal processing does effect characteristic taste of tender coconut water.

Yet tender coconut water beverages has managed to create a huge market with increasing demand as coconut is a change from fruit and carbonated beverage market. 
So efforts are made to produce a beverage from mature coconut water which go closely with consumers' perception of a coconut water beverage, using the market created for coconut water beverages.

Production of coconut water beverages particularly as a by product of processing operations such as coconut desiccation has long interested food manufactures. One hundred and fifty litres of coconut water is resulting from every 1000 nuts paired. This cause a major problem to producers of desiccated coconut as the disposal of this water cause environmental pollution in surrounding water bodies increasing BOD and COD levels.

So it is timely to produce a value added beverage from matured coconut water “which go closely with consumers' perception of a coconut water beverage. Thus I consider it is important to establish, beyond question a method of production for a value added product from matured coconut water to profitably utilize a by-product in copra industry leading to a cleaner production.

\subsection{Objectives.}

1) To produce a beverage that matches the target market using mature coconut and small or medium scale technology.

2) Studying the shelf life of the product. 


\title{
Chapter 02
}

\section{Literature Review}

\author{
Genus :Cocos \\ Species :nucifera
}

\subsection{Maturing of the nut}

Normal yielding coconut palm trees inflorescence at monthly intervals. Twelve months elapses between the period of the inflorescence and maturity of the fruit. At any year therefore the palm will be of twelve or more bunches of flowers at successive stages of development, each representing growth about a month. The cavity inside the nut develops itself in the second month. The size increase considerably reaching its maximum size normally in the sixth month and it is full with nut water during this period. The meat starts developing within and soft layer in the cavity increases its hardness and grows till the very end though the rate of developing ceilings as the nuts ripen to the end. (farar, 1957). With the growing thickness of kernel the cavity gets reduced in size. There is a progressive decrease in quantity of the water as the nuts chemical composition and the coconut water change during this period). Coconut water has its vital functions in the composition of fat in the kernel as well the development of the germination (Hai, et. al, 1959) Maximum amount of water has been reported in 6 months nuts by many workers in this project ( 1998; Kamala Devi and 1978; Jayalakshmi et. al, Marar, 1957). (1991) has reported that coconut water is found in small quantities in the third month of development of the nut and reaches maximum in the eighth month and declines thereafter as the nut ripens. The drink is at its optimum 
level of acceptability and economic viability for commercial use when the nuts are of 6 months maturity (Srivatsa and Sankarn, 1995) Ediriweera (1996) has reported that the water from nuts at the kurumba stage (about 220 days old) is best suited for drinking as a beverage since $\ldots$ use is highest during this stage besides maximum volume of water.

The water of tender coconut, technically the liquid endosperm, is the most nutritious wholesome beverage that the nature has provided for the people of the tropics to fight the sultry heat. It has calorific value of 17.4 perlo0gm (Davis, 1962). The normal $\mathrm{pH}$ of the tender coconut water varies between 4.9 and 5.2 (Srivatsa, et. al, 1999)

\subsection{Chemical Constituents}

The composition of coconut water varies depending on the variety, maturity of the nut, condition of the soil and climatic condition. The major chemical constituents of coconut water are sugars and minerals and minor ones are fat, proteins and other nitrogenous substances

\subsubsection{Sugars}

Sugars form an important constituent of the tender nut water. The concentration of sugars in the nut water steadily increases from about 1.5 percent to about $5-5.5$ per cent in the early months of maturation and then slowly falls reaching about 2 per cent at the stage of the full maturity of the nut. In the early stages of maturity sugars are in the forms of glucose and fructose (reducing sugars) and sucrose (non-reducing sugar) 
appears only in later stages, which increases with the maturity while the reducing sugars fall. In the fully mature nut approximately 50 per cent of the total sugars is sucrose (Krishna Marar, 1957). The quantity of total sugars, reducing sugars and non-r ¿ducing sugars in tender coconut water is found to vary from variety to variety and from place to place to place even at same maturity. Kamala Devi and Velayutham (1978), has reported that till the eight month reducing sugars formed the major portion of the total sugar content but afterwards non-reducing sugar predominated. In the study conducted by Chikkasubbanna, et. al (1990) it was found that both reducing sugars and non reducing sugars (hence total sugars) increased between sixth and seventh months of maturation. According to Jayalakshmi et.al (1986) the two major changes in the profile of sugars during maturation were the steep fall of total sugars per nut by more than 90 per cent and the disappearance of sugars .

\subsubsection{Minerals}

The tender coconut water contains most of the minerals such as potassium, sodium, calcium, phosphorous, iron, copper, sulphur and magnesium.Among the minerals more than half is potassium the concentration of which is markedly by influenced by potash manuring. Tender coconut water being rich in potassium and other minerals plays a major role in increasing the urinary output. The beneficial effect of diets high in potassium and magnesium contents in reducing stroke especially in incividuals with high blood pressure has been reported by Dr. Alberto M.D. Associate Professor of Nutrition and Epidemiology at Harvard Medical School of Public Health (Anonymous, 1998). Cnemical analysis of nut water in the different stages of development showed that we absolute amounts of N.B.K. Ca and $\mathrm{Mg}$ are maximum in 